\title{
Quantitative Real-time Reverse Transcriptase-PCR Profiling of Anthocyanin Biosynthetic Genes during Orange Fruit Ripening
}

\author{
Paola S. Cotroneo', Maria P. Russo, Manuela Ciuni, and Giuseppe Reforgiato Recupero \\ Miglioramento Genetico, CRA-Istituto Sperimentale per l'Agrumicoltura, 190 Corso Savoia, 95024 \\ Acireale (CT), Italy \\ Angela R. Lo Piero \\ DACPA, Facoltà di Agraria,Università di Catania, Via Santa Sofia, 95100 Catania, Italy
}

\begin{abstract}
AdDitional INDEX words. Citrus sinensis, CHS, ANS, UFGT, mRNA expression, blood orange flesh, anthocyanin content
ABstract. Genes encoding chalcone synthase (CHS), anthocyanidin synthase (ANS), and UDP-glucose-flavonoid 3-Oglucosyltransferase (UFGT), some of the enzymes of anthocyanin biosynthetic pathway, were assayed in two different experiments using quantitative real-time reverse transcriptase (RT)-PCR, in order to test their transcription levels in the flesh of blood and common orange [Citrus sinensis (L.) Osbeck] fruit, and to investigate their role in anthocyanin accumulation in the same tissue. The first experiment compared a blood orange and a common orange cultivar during seven different fruit maturation stages. This was followed by the test of 11 different genotypes at the end of the winter season. Data collected from the first experiment, over the blood orange cultivar, were statistically analyzed using the Pearson correlation coefficient. Results show that CHS, ANS, and UFGT mRNA transcripts are up- and co-regulated in the blood orange cultivar, whereas they are down-regulated in the common orange cultivar. There is evidence of correspondence between the target genes expression level and the content of the pigment assessed. The second test confirms this correlation and shows that enzyme synthesis levels and pigment accumulation, in plants grown under the same environmental conditions, are dependent on the differences occurring among the genotypes tested. These results suggest that the absence of pigment in the common orange cultivars may be caused by the lack of induction on the structural genes expression. This is the first report on the characterization of the relationships between biosynthetic genes expression and fruit flesh anthocyanin content in blood oranges.
\end{abstract}

The blood orange is the typical product of Sicilian citriculture and its red to purple pigmented rind and flesh makes the fruit more attractive. Red color in blood oranges is due to the presence of anthocyanins, the largest class of pigments among the flavonoids. They are secondary metabolites, widely spread in higher plants and produced in different organs, in response to a variety of developmental, environmental, and genetic cues (Mol et al., 1996). They serve various reproductive functions [e.g., in flower petals to attract pollinators, and in seeds and fruit to aid in seed dispersal (Holton and Cornish, 1995)] and they protect plant tissues against pathogens and damage from environmental conditions [e.g., ultraviolet (UV) irradiation, cold temperature (Dixon and Paiva, 1995) and water stress (Chalker-Scott, 1999)]. This class of pigmented molecules also possesses some important therapeutic properties for human health (Saija, 1994), functioning as antioxidants, anti-inflammatories, in epithelium repair and protection, and in modulation of capillary permeability. In conferring these properties to blood orange fruit, anthocyanins contribute to their commercial popularity and value, therefore research has been focusing on understanding the biosynthetic pathway for anthocyanins in oranges (Lo Piero et al., 2005;

Received for publication 3 Nov. 2005. Accepted for publication 9 Mar. 2006.We thank Cathie Martin of the Dept. of Genetics, John Innes Centre, Norwich Research Park, Colney, Norwich, U.K., and Fred Gmitter of the Univ. of Florida, Institute of Food and Agricultural Sciences, Citrus Research and Education Center, Lake Alfred, for their helpful support. We acknowledge the program "Piano Agrumicolo" funded by MIPAF (D.M. n 509889-4 May 2001) for financing the poject: "Ricerche e sperimentazioni nel settore dell'agrumicoltura italiana."

'To whom reprint requests should be addressed.E-mail address: breedcitr@ mail. gte.it
Moriguchi et al., 1999, 2001; Reforgiato et al., 2000). In Citrus L., anthocyanins are expressed in young shoots and fruit and some floral tissues of lemon [C. limon (L.) Burm. f.], citron (C. medica L.), and C. ichangensis Swing., and among the mature fruit, they are expressed exclusively in blood oranges and their hybrids. The major anthocyanins of the juice were characterized as cyanidin 3-glucoside and cyanidin 3-(6"'-malonylglucoside) (Fig. 1). Furthermore, six minor anthocyanins were detected and identified as cyanidin 3,5-diglucoside, delphinidin 3-glucoside, cyanidin 3 -sophoroside, delphinidin 3-(6"-malonylglucoside), peonidin 3-(6"'-malonylglucoside), and cyanidin 3-(6"-dioxalylglucoside) (Hillebrand et al., 2004). Isoenzymatic and molecular markers demonstrate that blood oranges and common oranges derived from the same segregation and recombination process (Reforgiato and Puleo, 1994; Torres et al., 1978). Other reports (Chandler, 1958) on blood oranges deriving from different parts of the world, show that blood orange germplasm from divergent sources shared a common ancestor. Unfortunately, classical genetic analysis of pigmentation is difficult in Citrus due to the long juvenile period and other reproductive factors associated with the genus. Thus, molecular characterization and studies of the expression levels of structural genes, involved in anthocyanin biosynthesis, represent important steps toward understanding the mechanism leading to anthocyanin accumulation in blood oranges and to the lack of pigments in the common oranges. The content of pigment varies greatly in blood oranges, during fruit maturation and depending on the genotype, the prevailing environmental conditions, and the storage temperature (Rapisarda et al., 2001). Moreover, anthocyanin content varies considerably between flesh and rind, causing problems for marketing the oranges. Consequently, the biosynthesis of these pigments needs to be studied, to develop 


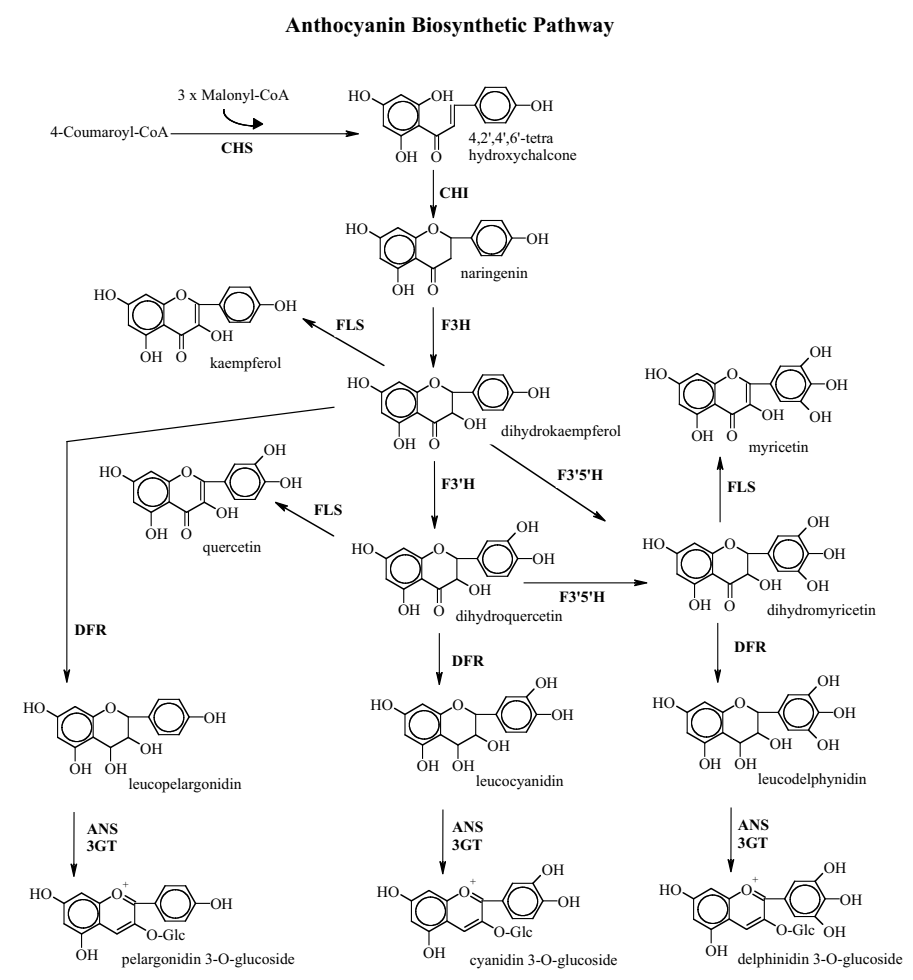

Fig. 1. Schematic representation of anthocyanin pathway. Flavonoids and anthocyanins are secondary metabolites of the same biosynthetic pathway. The first committed step is catalyzed by chalcone synthase (CHS), which uses malonyl-CoA and 4-coumaroyl-CoA as substrates. The main anthocyanic product in blood oranges is cyanidin 3-O-glucoside. $\mathrm{CHI}=$ chalcone flavanone isomerase, $\mathrm{F} 3 \mathrm{H}$ = flavanone 3'-hydroxylase, $\mathrm{F} 3 \mathrm{H}$ = flavanone 3'5'-hydroxylase, FLS = flavonol synthase, DFR = dihydroflavonol 4-reductase, ANS 3GT = last two enzymes of the pathway anthocyanidin synthase (ANS) and UDP-glucoseflavonoid 3-O-glucosyltransferase (UFGT).

the means for assisted selection of desirable pigment traits and to maintain a high quality of the product, by assuring constant pigment levels in fruit ripened under differing environmental conditions. Anthocyanin biosynthetic pathway has been studied in a great number of monocotyledonous and dicotyledonous species (Holton and Cornish, 1995). Pigmentation in flowers has been the most investigated; at least 35 genes are known to affect flower color in Petunia hybrida Vilm. (Gerats and Martin, 1992; Wiering and De Vlaming, 1984). Structural and regulatory genes encoding the biosynthetic enzymes have also been characterized and cloned in Zea mays L. (Paz-Ares et al., 1986; Radicella et al., 1991), Antirrhinum majus L., Perilla frutescens L. ex Jackson (Gong et al., 1997), and Arabidopsis thaliana (L.) Heynh. By contrast, the investigation of anthocyanin biosynthesis in fruit has been more limited and focused particularly on Malus $\times$ sylvestris (L.) Mill. var. domestica (Borkh.) Mansf. (Honda et al., 2002), Vitis vinifera L., V. vinifera x V. labrusca L. (Boss et al., 1996; Gollop et al., 2001; Kobayashi et al., 2001, 2002; Sparvoli et al., 1994), and Prunus persica (L.) Batch (Tsuda et al., 2004). Studies led to the conclusion that the pigment is synthesized when at least two kinds of genes are expressed: structural genes, encoding the enzymes catalyzing the reactions of the metabolic pathway, and regulatory genes, encoding the transcription factors controlling their expression (Dooner et al., 1991; Goodrich et al., 1992; Procissi et al., 1997; Quattrocchio et al., 1993). Therefore, any significant genetic occurrence, in even one of the structural or regulatory genes, may result in the loss of production of the pig- ment. In Citrus, the structural genes chalcone synthase (CHS), chalcone isomerase (CHI), flavanone 3-hydroxylase $(\mathrm{F} 3 \mathrm{OH})$, dihydroflavonol 4-reductase (DFR), anthocyanidin synthase (ANS), and UDP-glucose-flavonoid 3-O-glucosyltransferase (UFGT) were characterized and cloned (Lo Piero et al., 2005; Moriguchi et al., 1999, 2001; Reforgiato et al., 2000). Here we report results from analysis of the expression of genes encoding three of the enzymes of the anthocyanin biosynthetic pathway in Citrus (Fig. 1): CHS, which catalyzes the condensation of 4coumaroyl-CoA and malonyl-CoA to form chalconone naringenin, the first committed step of flavonoid biosynthesis; ANS, which catalyzes the conversion of flavan-3,4,-diols (leucoanthocyanidins) to 3-OH-anthocyanidins; and UFGT, which catalyses the conversion of 3-OH-anthocyanidins to anthocyanins, which are the last steps of the pathway. In order to achieve some information about the expression of these genes, Citrus cDNA sequences were used to design TaqMan probes to be used in two experiments of quantitative real-time reverse transcriptase (RT)-PCR. The first experiment was intended to quantify and compare gene expression levels during maturation in a blood orange and a common orange selection. The second experiment looked at the expression of these genes in fruit of 11 different cultivars and selections collected at the end of winter season, in which period cold induction had allowed strong pigmentation of each cultivar to develop. These results were compared with the analysis of anthocyanin content in the same samples, to characterize the relationships between the expression of the biosynthetic genes and the accumulation of anthocyanin.

\section{Materials and Methods}

Plant material. The orange fruit used in both the experiments were collected from plants of the same age, grafted on sour orange (C. aurantium L.), grown under the same pedo-climatic conditions at the experimental orchard of the Consiglio per la Ricerca e la Sperimentazione in Agricoltura-Istituto Sperimentale per l'Agrumicoltura, located in Palazzelli (Siracusa), Italy.

For both the tests performed, fruit of each genotype were collected from three different trees, 10 representative fruit from each tree, for a total of 30 fruit per genotype. Fruit were immediately processed: samples were cut into two halves. One-half of each fruit was used for molecular analysis and the remaining half was used for chemical analysis.

Samples of $C$. sinensis '58-8D-1' nucellar 'Moro' selection (a blood orange) and of $C$. sinensis 'Vainiglia' (a common orange) were collected at seven progressive stages of fruit maturation: $\mathrm{I}=$ 19 Oct. 2001 , II $=9$ Nov. 2001 , III = 29 Nov. 2001 , IV $=18$ Dec. 2001, V = 8 Jan. 2002, VI = 31 Jan. 2002, VII = 21 Feb. 2002.

Samples of each one of the 11 different genotypes (Table 1) were collected on 14 Mar. 2002, by which time winter temperatures had allowed a good level of anthocyanin pigmentation to develop. They comprised nine $C$. sinensis blood orange cultivars or selections, expressing different levels of flesh pigmentation; one hybrid, 'OTA 9', obtained crossing $C$. reticulata Blanco 'Oroval' clementine selection with $C$. sinensis 'Tarocco' orange and a common orange as control, $C$. sinensis 'Cadenera'.

Total Ribonucleic ACID (RNA) isOlation ANd REAL-TIME AMPLIFICATION PROCEDURES. Oranges' fruit flesh (juice vesicles) was isolated from albedo tissue and segment epidermis, immersed in a mortar containing liquid nitrogen and pulverized using a pestle. A 3-g aliquot was homogenized in TRIZOL LS Reagent (Invitrogen Corp., Carlsbad, Calif.). An additional isola- 
Table 1. Eleven Citrus genotypes tested in quantitative real-time reverse transcriptase-PCR.

\begin{tabular}{ll}
\hline Accession & \multicolumn{1}{c}{ Origin } \\
\hline OTA 9 & C. reticulata 'Oroval' clementine X C. sinensis 'Tarocco' \\
58-8D-1 Russo & nucellar line of $C$. sinensis 'Moro' \\
'Stefano Fontanazza' late selection & old line of $C$. sinensis 'Tarocco' \\
Tapi & nucellar line of $C$. sinensis 'Tarocco Arcimusa' \\
C5787 & nucellar line of $C$. sinensis 'Tarocco Lempso' \\
C5083 & nucellar line of $C$. sinensis 'Tarocco Giarretta' \\
C1882 & nucellar line of $C$. sinensis 'Tarocco Sciara' \\
D2071 & nucellar line of $C$. sinensis 'Tarocco Scirè' \\
AMOA17 & poorly pigmented nucellar line of $C$. sinensis 'Moro' \\
C1665 & nucellar line of $C$. sinensis 'Tarocco Messina' \\
Biondo Cadenera & C. sinensis common orange \\
\hline
\end{tabular}

tion step by centrifugation was performed to remove proteins, fat, polysaccharides, extra cellular and insoluble material from the homogenate. Chloroform phase separation was followed by isopropanol RNA precipitation and by $75 \%$ ethanol RNA wash. RNA was then redissolved in RNase free water.

For quantitative real-time RT-PCR $50-\mu \mathrm{L}$ reaction volumes were used, following the protocol of the Platinum Quantitative RT-PCR ThermoScript One-Step System (Invitrogen), adding to the mix $1 \mu \mathrm{L}$ of ROX Reference Dye (Invitrogen) and $10 \mu \mathrm{L}$ of 75 $\mathrm{ng} \cdot \mu \mathrm{L}^{-1}$ RNA sample. Reactions were conducted in an ABIPRISM 7000 Sequence Detection System (Applied Biosystems, Foster City, Calif.), with 1 cycle of $60{ }^{\circ} \mathrm{C}$ for $30 \mathrm{~min}$ (cDNA synthesis) and $95^{\circ} \mathrm{C}$ for $5 \mathrm{~min}$ (pre-denaturation), followed by 40 cycles 95 ${ }^{\circ} \mathrm{C}$ for $15 \mathrm{~s}$ (denaturation), $60^{\circ} \mathrm{C}$ for $1 \mathrm{~min}$ (annealing/extension). For the specific detection of mRNA, primers and TaqMan probes (Table 2) were designed using the ABI PRISM Primer Express version 2.0.0 (Applied Biosystems), according to quantitative real-time RT-PCR requirements, from the CitCHS (AB009351), ANS (AY500593) and UFGT (CF972319) sequences, and from C. sinensis elongation factor 1-alpha (EF1) (AY498567), a housekeeping gene assumed not to be regulated significantly in either control or test tissues, used as endogenous control. The analysis of each sample was replicated three times, one positive and two negative controls were performed (no template and no amplification control); absence of genomic DNA in RNA preparations was verified by omitting the reverse transcriptase and substituting a
Taq DNA polymerase in the reaction.

QuANTITATIVE REAL-TIME RT-PCR DATA ANALYsis. The analytic method used was the relative quantification standard curve method. Data collected from the sequence detection system were expressed as $\mathrm{Ct}$ (threshold cycle for target amplification) values and treated as follows. Data for the genes of interest (CHS, ANS, and UFGT) were compared to data for the endogenous control gene EF. Standard curves were constructed for each target gene and for the endogenous control. The log input amount for the unknown samples was calculated using the formula: $\left[\left(\mathrm{C}_{\mathrm{t}}\right.\right.$ value $)$ $-\mathrm{y}] / \mathrm{m}$, where $\mathrm{y}=$ standard curve intercept value and $\mathrm{m}=$ standard curve slope value, and the final input amount was calculated by the formula: $10^{\wedge}$ ( $\log$ input amount). The units of the calculated amount are the same as the units used to construct the standard curve, which are nanograms of total RNA. The amount of the gene of interest was then divided by the amount of endogenous control gene to determine the normalized amount of target. The sample showing the lowest expression level of each target gene was then designated arbitrarily as calibrator for all the samples analyzed for that gene. Final expression values refer to fold-increase relative to the endogenous control gene.

Pearson correlation coefficient statistical analysis was performed by means of STATISTICA software (version 6; StatSoft, Tulsa, Okla.). Correlations were marked significant for $P=0 ; \mathrm{n}=$ 21. Evidence of co-regulation was found for values approximated to $r=+1$ (perfect positive correlation).

Table 2. Specific primers and TaqMan probes used in quantitative real-time reverse transcriptase-PCR.

\begin{tabular}{|c|c|c|c|c|}
\hline \multirow{2}{*}{$\begin{array}{l}\text { Gene } \\
\text { detected }\end{array}$} & \multicolumn{2}{|r|}{ Primer/TaqMan probe (FAM/Tamra) } & \multirow{2}{*}{$\begin{array}{c}\text { Annealing } \\
\text { temp } \\
\left({ }^{\circ} \mathrm{C}\right)\end{array}$} & \multirow{2}{*}{$\begin{array}{c}\text { Amplicon } \\
\text { size } \\
\text { (bp) }\end{array}$} \\
\hline & Name & Sequence & & \\
\hline \multirow[t]{3}{*}{$\overline{\mathrm{EF}^{2}}$} & EF-161_fw & 5'-CTGCTGGACGCTCTTGACAA-3' & 60 & 73 \\
\hline & EF-88_rv & 5'- TCCTGGAGTGGCAGACGAA-3' & 60 & \\
\hline & EF-161-88 (probe) & 5'-ATCAATGAGCCGAAGAGGCCCTCAGA-3' & 60 & \\
\hline \multirow[t]{3}{*}{ CHS } & CHS-261_fw & 5'-TGACACCCATCTCGATAGTCTTGT-3' & 60 & 72 \\
\hline & CHS-333_rv & 5'-GGCGCCGATGATAATAGCA-3' & 60 & \\
\hline & CHS-261-333 (probe) & 5'-CCTTGTTTGGCGATGGTGCGG-3’' & 60 & \\
\hline \multirow{3}{*}{ ANS } & ANS-702_fw & 5'-TCACTTTCATTCTTCACAACATGGT-3' & 60 & 69 \\
\hline & ANS-771_rv & 5'-TTAGCAGTCACCCATTTGTCTTTG-3' & 60 & \\
\hline & ANS-702-771 (probe) & 5'-CCGGGCCTGCAGCTCTTCT-3' & 60 & \\
\hline \multirow[t]{3}{*}{ UFGT } & UFGT-191_fw & 5'-TCACTTCATTCCAGGAATGAATAAGA-3' & 60 & 71 \\
\hline & UFGT-262_rv & $5^{\prime}$-TCCAAGTCTCCGGAAACAACTC-3' & 60 & \\
\hline & UFGT-191-262 (probe) & 5'ACGCGTCGCCGACTTGCCTG-3' & 60 & \\
\hline
\end{tabular}

$\overline{\mathrm{z}} \mathrm{EF}=$ elongation factor 1-alpha (AY498567), CHS = chalcone synthase (AB009351), ANS = anthocyanidin synthase (AY500593), UFGT = UDP-glucose-flavonoid 3-O-glucosyltransferase (CF972319). 
Total anthocyanin content. Anthocyanins determination was performed by $\mathrm{pH}$-differential spectrophotometry (UV/vis mini 1240; Shimadzu Corp., Tokyo) according to the method described in Wrolstad (1976), with slight modifications. Briefly, aliquots $(1 \mathrm{~g})$ of orange flesh were frozen in liquid nitrogen, powdered by mortar and pestle, and, successively extracted with $1 \mathrm{~mL}$ of water by vigorous shaking for $1 \mathrm{~h}$ at $4{ }^{\circ} \mathrm{C}$. Samples were centrifuged at $12,000 g_{n}$ for $20 \mathrm{~min}$, then the supernatant was recovered and an aliquot dissolved in buffer solution 1 at $\mathrm{pH}$ $1.0(55 \mathrm{~mm} \mathrm{KCl}, 0.145 \mathrm{~N} \mathrm{HCl})$ and in buffer solution 2 at $\mathrm{pH} 4.5$ $\left(0.2 \mathrm{M} \mathrm{CH}_{3} \mathrm{COONa}\right)$. The absorbance was measured at $510 \mathrm{~nm}$. Anthocyanin content was calculated using the following formula: percent $\mathrm{p} / \mathrm{p}=[(\mathrm{Abs} \mathrm{pH} 1.0-\mathrm{Abs} \mathrm{pH} 4.5) / \varepsilon \times \mathrm{L}) \times \mathrm{MW} \times \mathrm{DF}$ $\times\left(\mathrm{V} / \mathrm{W}_{\mathrm{t}}\right) \times 100 \%$, where Abs $=$ absorbance, $\varepsilon=$ cyanidin-3-Oglucoside molar absorbance $(26,900), \mathrm{L}=$ cell path length (usually $1.0 \mathrm{~cm}), \mathrm{MW}=$ cyanidin-3-O-glucoside molecular weight (449.2), $\mathrm{DF}=$ dilution factor, $\mathrm{V}=$ final volume (milliliters), $\mathrm{W}_{\mathrm{t}}$ = sample weight (milligrams).

\section{Results}

RELATIVE TRANSCRIPT LEVELS OF ANTHOCYANIN BIOSYNTHETIC GENES AND ANTHOCYANIN CONTENTS IN 'MORO' AND 'V AINIGLIA' ORANGE FLESH SAMPLES IN SEVEN PROGRESSIVE STAGES OF FRUIT MATURATION. The results of quantitative real-time RT-PCR performed on 'Moro' and 'Vainiglia' orange flesh samples during fruit maturation (Figs. 2 and 3) showed a significant difference in the expression of the three enzyme's transcripts in blood oranges and common oranges, in accordance with the different anthocyanin content of the fruit flesh. 'Moro' orange (Fig. 2) showed a steep and constant rise in CHS, ANS, and UFGT transcript levels, increasing during the entire period of maturation excepting the fifth sampling period, showing a dramatic decrement in the expression levels of the three genes. Significantly the transcript levels of the enzymes appeared to vary coordinately in this cultivar (Table 3 ). Total anthocyanins in 'Moro' orange (Fig. 2) were undetectable in the first two samplings, their level beginning to rise from the third sampling onward, remaining below $2 \mathrm{mg} / 100 \mathrm{~g}$ in the fourth and fifth samplings, increasing in the sixth and reaching $22.2 \mathrm{mg} / 100$ $\mathrm{g}$ in the last sample. There was a direct correlation between the transcript levels for CHS, ANS, and UFGT gene expression at a given stage of fruit maturation and the accumulation of pigment at the same stages (Table 3). 'Vainiglia' orange exhibited negligible traces of the synthesis, especially for CHS and ANS, at all stages of fruit maturation, with low and insignificant fluctuations within the different samplings, and almost undetectable levels at the seventh sample, whereas the UFGT curve showed slightly higher oscillations within the seven samplings, with peaks in the first, the third and the sixth samples. In 'Vainiglia' orange anthocyanin production was never detected.

MRNA TRANSCRIPT LEVELS AND ANALYSIS OF ANTHOCYANIN CONTENT IN FLESH OF 11 CITRUS GENOTYPES. Real-time results (Fig. 4) showed that the expression of the analyzed genes varied widely among the 11 genotypes tested. Generally, as predicted, very high, high, medium, or poorly pigmented samples synthesized respectively very high, high, medium, or low mRNA target levels, in interdependent quantities, presumably coordinately regulated. Slightly different was the case of $C$. sinensis 'AMOA 17 ', a somatic mutation of 'Moro' orange, presenting a lower reliable expression of CHS and ANS (19.76-fold vs. 2.52-fold, the highest level for CHS and the lowest for ANS among the poorly pigmented) and the complete absence of UFGT. 'Cadenera' orange lacked expression of CHS and ANS, whereas it did express traces of UFGT, confirming the results obtained in the previous experiment. Anthocyanin build-up in the flesh of fruit picked in mid March (Fig. 4) varied substantially, from a maximum of 34.3 $\mathrm{mg} / 100 \mathrm{~g}$ tissue in 'OTA 9' to a minimum of $0.25 \mathrm{mg} / 100 \mathrm{~g}$ in C. sinensis 'Tarocco Messina'.

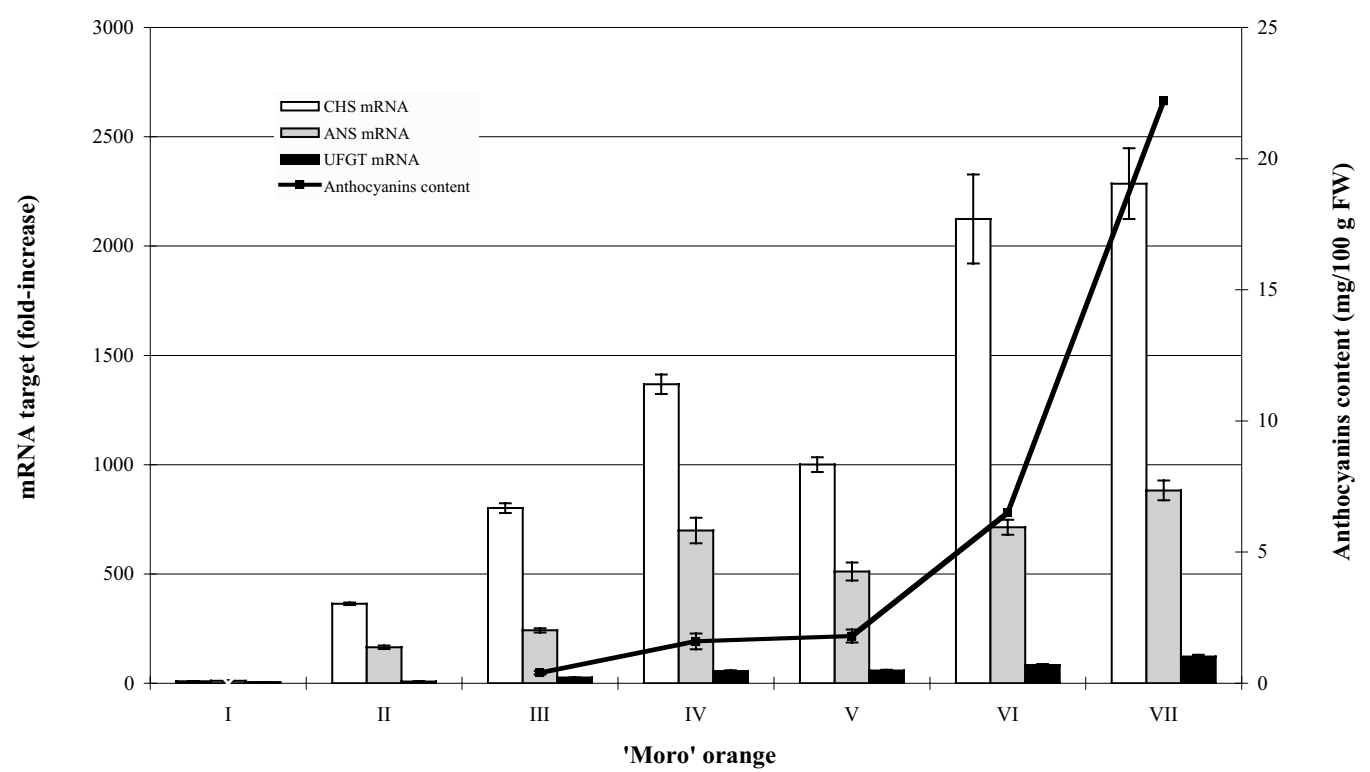

Fig. 2. Quantitative real-time reverse transcriptase-PCR detection of anthocyanin biosynthesis genes and $\mathrm{pH}$-differential spectrophotometry determination of total anthocyanins content in the flesh of 'Moro' orange. CHS = chalcone synthase, ANS = anthocyanidin synthase, UFGT = UDP-glucose-flavonoid 3-O-glucosyltransferase. Fruit were collected at seven different progressive maturation stages, approximately every 3 weeks $(I=19$ Oct. 2001 , II $=9$ Nov. 2001 , III $=29$ Nov. 2001, IV = 18 Dec. 2001, V = 8 Jan. 2002, VI = 31 Jan. 2002, VII = 21 Feb. 2002). mRNA level of each enzyme increases and decreases coordinately in this cultivar. No pigment increase was observed between samplings four and five, a time during which there was a slight decrease in all three mRNA levels. This is consistent with the generally positive correlation seen between pigment accumulation and mRNA abundance. 


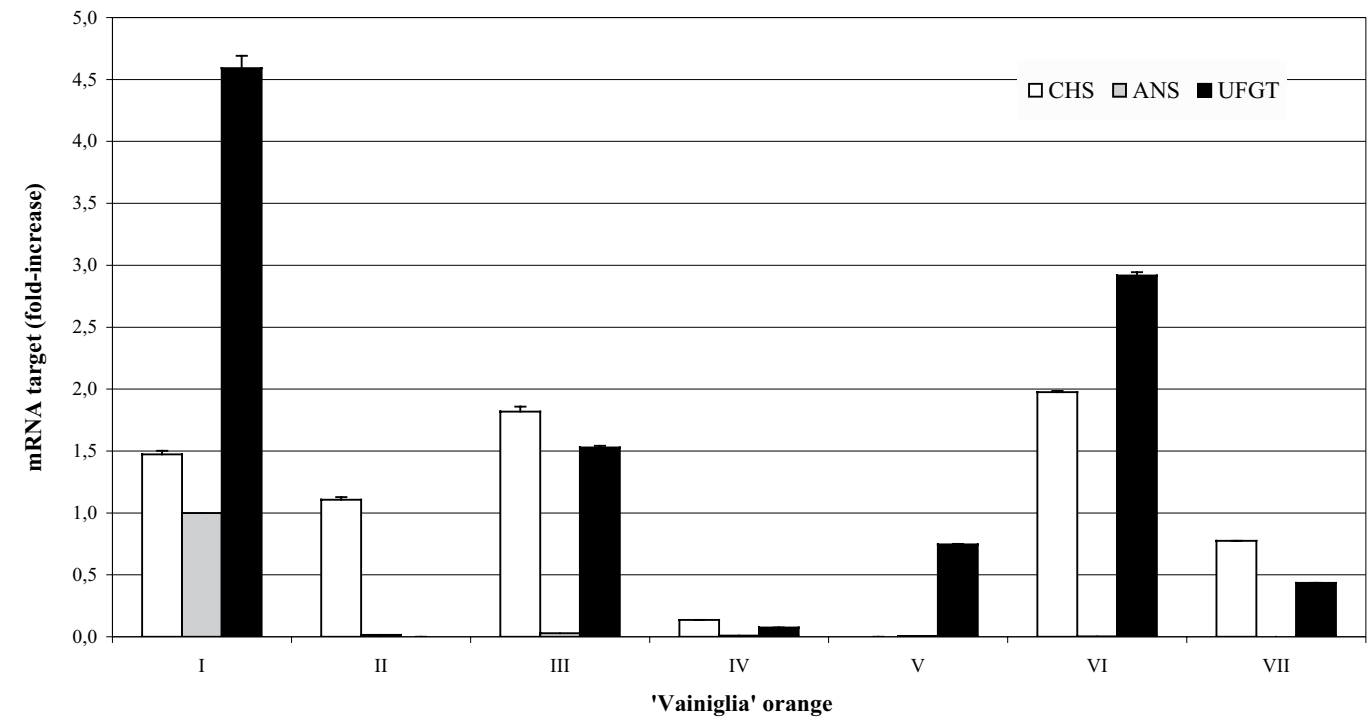

Fig. 3. Quantitative real-time reverse transcriptase-PCR detection of anthocyanin biosynthesis genes and $\mathrm{pH}$-differential spectrophotometry determination of total anthocyanins content in the flesh of 'Vainiglia' orange. CHS = chalcone synthase, ANS = anthocyanidin synthase, UFGT = UDP-glucose-flavonoid 3-O-glucosyltransferase. Fruit were collected at seven different progressive maturation stages, approximately every 3 weeks (I = 19 Oct. 2001, II = 9 Nov. 2001 , III = 29 Nov. 2001, IV = 18 Dec. 2001, V = 8 Jan. 2002, VI = 31 Jan. 2002, VII = 21 Feb. 2002). Data shown explain the absence of pigment in the common orange cultivar and strongly suggest that target genes are not missing, but down-regulated.

between samplings four and five, a time during which there was a slight decrease in all three mRNAlevels, this is consistent with the generally positive correlation seen between pigment accumulation and mRNA abundance.

CHS is the first enzyme committed to the biosynthesis of all classes of flavonoids in plants, according to Sparvoli et al. (1994). Enzymes that act later in the flavonoid pathway are encoded by a single active gene, whereas those that act early in this pathway are encoded by larger gene families. Two CHS genes were isolated in Citrus, CitCHS1 and CitCHS2, by Moriguchi et al. (2001), where changes in flavonoids in satsuma mandarin (C. unshiu Marc.) were analyzed in relation to CHS gene expression in developing

Table 3. Pearson correlation coefficient of chalcone synthase (CHS), anthocyanidin synthase (ANS) and UDP-glucose-flavonoid 3-Oglucosyltransferase (UFGT) target genes among them and with anthocyanin content in 'Moro' orange experiment.

\begin{tabular}{lccc}
\hline & & & $\begin{array}{c}\text { Anthocyanin } \\
\text { content } \\
\text { mg/100 g FW }\end{array}$ \\
\hline CHS & ANS & UFGT & $r=0.7688$ \\
& $P=0$ & $r=0.8705$ & $P=0$ \\
ANS & $P=0$ & $r=0.5783$ \\
& & $r=0.8185$ & $P=0$ \\
UFGT & $P=0$ & $r=0.8827$ \\
& & $P=0$ \\
\hline
\end{tabular}

$\overline{\mathrm{z} \text { Evidence of correlation was found for values approximated to } \mathrm{r}=+1}$ (perfect positive correlation).

\section{Discussion}

Our results for CHS, ANS, and UFGT transcript levels support the coordinate expression of these structural genes in the same, or in concurrent, biosynthetic pathways (Fell, 1997). Besides they demonstrate that the enzymes' expression in blood orange fruit is positively correlated with anthocyanin accumulation. Data shown explain the absence of pigment in the common orange cultivar and strongly suggest that target genes are not missing, but down-regulated. These data are confirmed by our second experiment on various blood orange genotypes, where fruit containing higher levels of anthocyanin show higher expression of the structural genes.

In the first experiment on 'Moro' orange the transcript levels of the three genes analyzed increased synchronously, resulting in two peaks at the fourth and seventh samplings (Fig. 2). Analysis performed by $\mathrm{pH}$-differential spectrophotometry on total anthocyanin content shows it to be closely related to the enzyme synthesis level assayed. There was virtually no pigment increase observed citrus fruit. The flavonoid contents in juice sacs/segment epidermis decreased with ripening, to a minimum value next to zero in fruit $180 \mathrm{~d}$ after flowering, and CitCHS 1 and CitCHS2 levels were decreasing in the approach to ripening. The last sampling analyzed in Moriguchi et al. (2001) corresponds to our first, so we were able to assume that the strong association between CHS transcript levels and anthocyanin production suggests that the CHS we analyzed is produced exclusively for anthocyanin biosynthesis, during these developmental periods, moreover the assumption is strengthened by the extremely low expression of the enzyme in the common orange cultivar. Finally this was also confirmed by Pearson correlation coefficient, which showed results approximated to the perfect positive correlation for the target genes among them, and between target genes and anthocyanin content, confirming that the enzymes tested belong to anthocyanin metabolic pathway (Table 3).

Kobayashi et al. $(2001,2002)$ suggested that in white cultivars of grape (V. vinifera) and in their sports with red skin, the phenotypic change is the result of a mutation in $M y b A$, a regulatory gene controlling the expression of UFGT. A precedent work (Lo Piero et al., 2005) showed that common oranges' flesh does not express UFGT. In this work, because of the greater sensitivity of the technique used, we were able to detect particularly small quantities of transcripts, and to quantify them within a lower range of error. Even if the three target mRNAs are in some cases almost undetectable, they are not missing. Moreover other experiments on differential screening of clones isolated, by means of the PCR-select technique, from a blood orange and a common orange cultivar (M.P. Russo, personal communication) have pointed out the presence of the same genes down-regulated in the common orange cultivar. This fact led us to the conclusion that the absence of pigment in the flesh of common orange fruit might depend on some other regulatory mechanism.

In maize (Zea mays L.) the regulation requires two classes of transcription factors, one class containing a bHLH motif of the transcription activator $M y c$ ( $B$ and $R$ ), and the other containing 


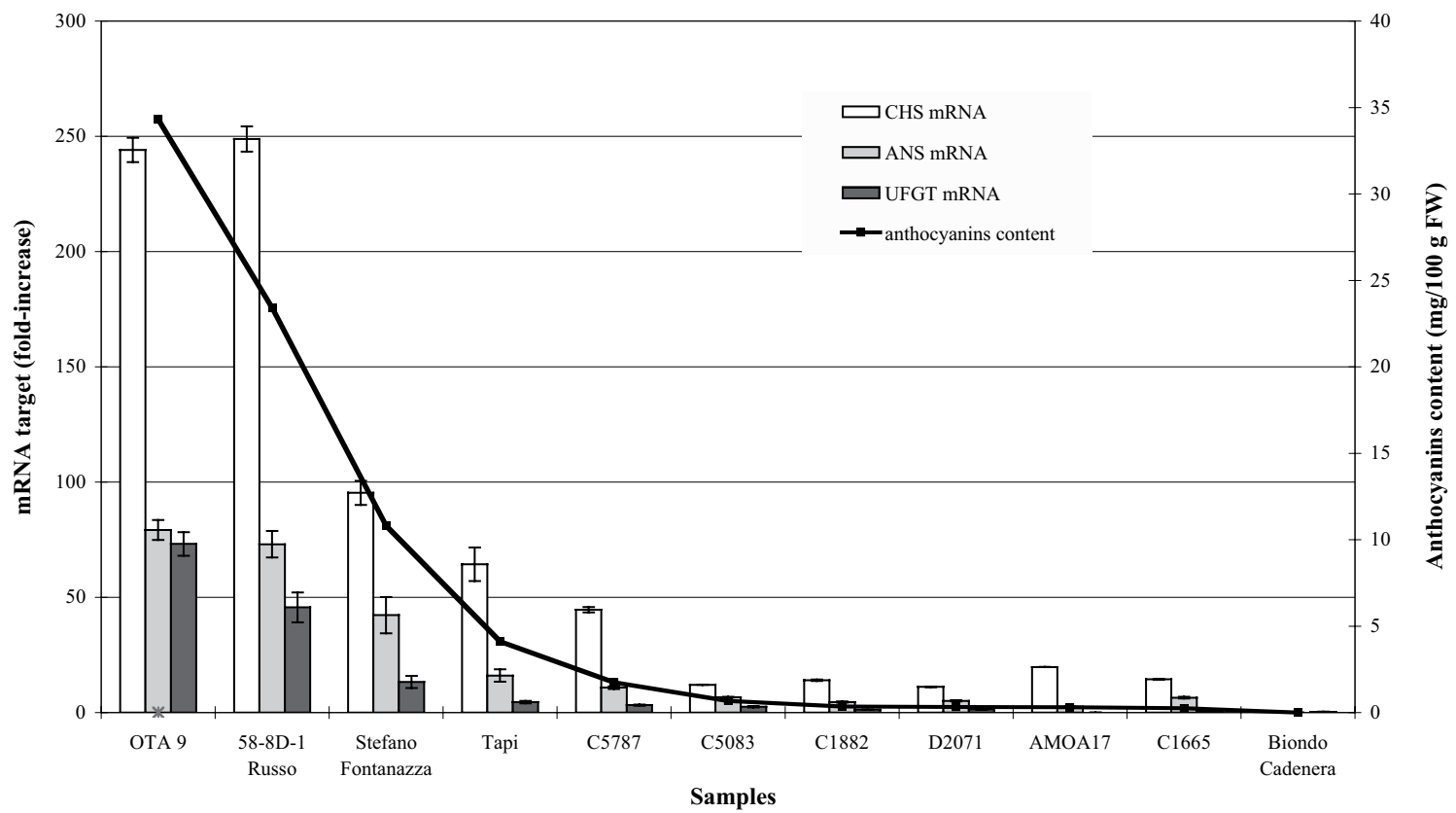

Fig. 4. Quantitative real-time reverse transcriptase-PCR detection of anthocyanin biosynthesis genes and pH-differential spectrophotometry determination of total anthocyanins content in the flesh of 11 citrus genotypes collected at the end of winter season (14 Mar. 2002). CHS = chalcone synthase, ANS = anthocyanidin synthase, UFGT = UDP-glucose-flavonoid 3-O-glucosyltransferase. Samples are described in Table 1. The enzymes' expression levels showed by '58-8D-1 Russo' nucellar 'Moro' selection are 10-fold lower than levels shown in Fig. 1 for the same selection. This is due to March warmer temperature, which allows a minor anthocyanin synthesis. Fruit containing higher levels of anthocyanin show higher expression of the structural genes.

a $\mathrm{Myb}$ domain $(\mathrm{Cl}$ and $\mathrm{Pl})$; in the plant tissues the activation of the genes of the pathway and the purple pigmentation are consequential to the combined action of $P l$ with one or the other bHLH factors, encoded by either $r$ (red) or $b$ (booster) loci (Dooner et al., 1991; Goff et al., 1990, 1992). Each regulator determines the pigmentation of a different part of the plant and controls time, distribution and level of the expression, by activating, alternatively or coordinately, single structural or regulatory genes (McCarty et al., 1991), or groups of them (Chandler et al., 1989; Cone and Burr 1989; Cone et al., 1993, Dellaporta et al., 1988; Ludwig et al., 1989; Paz-Ares et al., 1987; Perrot and Cone 1989; Tonelli et al., 1991). Homologous genes have been characterized in $A$. majus (Goodrich et al., 1992) and P. hybrida (Quattrocchio et al., 1993). In Citrus regulatory genes involved in anthocyanin biosynthesis have not yet been isolated. We might hypothesize that purple pigment, in the flesh of blood oranges, is synthesized in response to a similar mechanism of interaction between the two classes of genes $M y b$ and $M y c$-like. The evident distinction between the characteristic absence of pigment in the common orange, and the trait variable expression of the blood orange phenotype, might be explained on the basis of the complexity of the regulatory control, which might also be responsible of the two distinct evolutionary ways followed by blood oranges and common oranges.

Moreover, 'Vainiglia' orange, showing higher UFGT than the other two genes' mRNA transcript levels, although still inconsequential, suggests that the lower content of the two other structural genes transcripts might be caused by two different regulatory genes, one regulating CHS and ANS together and the other acting on UFGT. Where CHS and ANS are down-regulated the consequential lack of 3-OH-anthocyanidins, substrate for UFGT, could probably cause the lack of incremental increase of this last enzyme. In this case UFGT would not be directly silenced neither activated, showing only a basic level of expression. UFGT is not the key enzyme to explain the lack of pigmentation in oranges, as it was also found in peach (P. persica) by Tsuda et al. (2004).

In the test on the 11 genotypes at maturity, the quantity of pigment measured results from a five months period of accumulation, whereas mRNArecorded levels are the expression of a momentary transcription event, so no perfectly reliable anthocyanin content and genes expression levels were expected, but clear evidence of the involvement of the genes in the biosynthetic pathway and of the coordinate regulation of the target genes was demonstrated. The transcription activation mechanisms for each gene may be different in the different genotypes, which may react differently to environmental conditions.

Our studies have not yet led to an absolute explanation for the differences in anthocyanin accumulation in blood oranges and common oranges. The regulation of the pathway is presumably different in the different tissues of the fruit, as well. Differences in the expression pattern may occur even between fruit rind and flesh, as oranges presenting pigmented rind always have pigmented flesh, but not all blood flesh fruit show blood rinds. Further studies to identify and verify the role of regulatory sequences are in progress. Two cDNA sequences, showing structural similarities with proteins of the $M y b$ and $M y c$ transcription factors family, were isolated from total RNA of 'Moro' orange and their implication in the regulation of anthocyanin's biosynthetic pathway is being verified. The results of a suppression subtractive hybridisation to identify and understand the role of genes differentially expressed in blood and common orange cultivars are in press.

\section{Literature Cited}

Boss, P.K., C. Davies, and S.P. Robinson. 1996. Expression of anthocyanin biosynthesis pathway genes in red and white grapes. Plant Mol. Biol. 32:565-569. 
Chalker-Scott, L. 1999. Elevated ultraviolet-B radiation induces crossprotection to cold in leaves of rhododendron under field conditions. Photochem. Photobiol. 79:199-204.

Chandler, B.V. 1958. Anthocyanin of blood oranges. Nature 4:933.

Chandler, V.L., J.P. Radicella, T.P. Robbins, J. Chen, and D. Turks. 1989. Two regulatory genes of the maize anthocyanin pathway are homologous: Isolation of $B$ utilizing $R$ genomic sequences. Plant Cell 1:1175-1183.

Cone, K.C. and B. Burr. 1989. Molecular and genetic analysis of light requirement for anthocyanin synthesis in maize, p. 143-146. In: D.E. Styles, G.A. Gavazzi, and M.L. Racchi (eds.). The genetics of flavonoids. Unicopli, Milan, Italy.

Cone, K.C., S.M. Cocciolone, F.A. Burr, and B. Burr. 1993. Maize anthocyanin regulatory gene $p l$ is a duplicate of $c l$ that functions in the plant. Plant Cell 5:1795-1805.

Dellaporta, S.L., I.M. Greenblatt, J.L. Kermicle, J.B. Hicks, and S.R. Wessler. 1988. Molecular cloning of the $R-n j$ gene by transposon tagging with $A c$, p. 263-282. In: J.P. Gustafson and R. Appels (eds.). Impact of new concepts. Plenum Press, New York.

Dixon, R.A. and N.L. Paiva. 1995. Stress-induced phenylpropanoid metabolism. Plant Cell 7:1085-1097.

Dooner, H.K., T.P. Robbins, and R.A. Jorgensen. 1991. Genetic and developmental control of anthocyanin biosynthesis. Annu. Rev. Genet. 25:173-199.

Fell, D.A. 1997. Understanding the control of metabolism. Portland Press, London.

Gerats, A.G.M. and C. Martin. 1992. Flavonoid synthesis in Petunia hybrida: Genetic and molecular biology of flower colour, p. 165-199. In:H.A. Stafford and R.K. Ibrahim (eds.). Advances in phytochemestry. Plenum Press, New York.

Goff, S.A., T.M. Klein, B.A. Roth, M.E. Fromm, K.C. Cone, J.P. Radicella, and V.L. Chandler, 1990. Transactivation of anthocyanin biosynthetic genes following transfer of $b$ regulatory genes in maize tissues. EMBO J. 9:2517-2522.

Goff, S.A., K.C. Cone, and V.L. Chandler. 1992. Functional analysis of the transcription activator encoded by the maize $B$ gene: Evidence for a direct functional interaction between two classes of regulatory proteins. Genes Dev. 6:864-875.

Gollop, R., S. Farhi, and A. Perl. 2001. Regulation of the leucoanthocyanidin dioxygenase gene expression in Vitis vinifera. Plant Sci. 161:579-588.

Gong, Z., M. Yamazaki, M. Sugiyama, Y. Tanaka, and K. Saito. 1997. Cloning and molecular analysis of structural genes involved in anthocyanin biosynthesis and expressed in a forma-specific manner in Perilla frutescens. Plant Mol. Biol. 35:915-927.

Goodrich, J., R. Carpenter, and E.S. Coen. 1992. Acommon gene regulates pigmentation pattern in diverse plant species. Cell 68:955-964.

Hillebrand, S., M. Schwarz, and P. Winterhalter. 2004. Characterization of anthocyanins and pyranoanthocyanins from blood orange [Citrus sinensis (L.) Osbeck] juice. J. Agr. Food Chem. 52:7331-7338.

Holton, T.A. and E.C. Cornish. 1995. Genetics and biochemistry of anthocyanin biosynthesis. Plant Cell 7:1071-1083.

Honda, C., N. Kotoda, M. Wada, S. Kondo, S. Kobayashi, J. Soejima, Z. Zhang, T. Tsuda, and T. Moriguchi. 2002. Anthocyanin biosynthetic genes are coordinately expressed during red coloration in apple skin. Plant Physiol. Biochem. 40:955-962.

Kobayashi, S., M. Ishimaru, C.K. Ding, H. Yakushiji, and N. Goto. Feb 2001. Comparison of UDP-glucose-flavonoid3-O-glucosyltransferase (UFGT) gene sequences between white grapes (Vitis vinifera) and their sports with red skin. Plant Sci. 160(5):543-550.

Kobayashi, S., M. Ishimaru, K. Hiraoka, and C. Honda. 2002. Myb-related genes of the Kyoho grape (Vitis labruscana) regulate anthocyanin biosynthesis. Planta 215:924-33.

Lo Piero, A.R., A. Consoli, I. Puglisi, G. Orestano, G. Reforgiato Recupero, and G. Petrone. 2005. Anthocyaninless cultivars of sweet orange lack to express the UDP-glucose flavonoid 3-O-glucosyl transferase. J. Plant Biochem. Biotechnol. 14:1-6.
Ludwig, S.R., L.F. Habera, S.L. Dellaporta, and S.R. Wessler. 1989. Lc, a member of the maize $R$ gene family responsible for tissue specific anthocyanin production, encodes a protein similar to transcriptional activators and contains the myc-homology region. Proc. Natl. Acad. Sci. 86:7092-7096.

McCarty, D.R., T. Hattori, C.B. Carson, V. Vasil, M. Lazar, and I.K. Vasil. 1991. The Viviparous-1 developmental gene of maize encodes a novel transcriptional activator. Cell 66:895-905.

Mol J., G.I. Jenkins, E. Schafer, and D. Weiss. 1996. Signal perception, transduction and gene expression involved in anthocyanin biosynthesis. Critical Rev. Plant Sci. 15:525-557.

Moriguchi, T., M. Kita, Y. Tomono, T. Endo-Inagaki, and M. Omura. 1999. One type of chalcone synthase gene expressed during embryogenesis regulates the flavonoid accumulation in citrus cell cultures. Plant Cell Physiol. 40:651-655.

Moriguchi, T., M. Kita, Y.Tomono, T.Endo-Inagaki, and M. Omura. 2001. Gene expression in flavonoid biosynthesis: Correlation with flavonoid accumulation in developing citrus fruit. Physiol. Plant. 111:66-74.

Paz-Ares, J., U. Wienand,P.A. Peterson, and H. Saedler. 1986. Molecular cloning of the $c$ locus of Zea mays: A locus regulating the anthocyanin pathway. EMBO J. 5:829-833.

Paz-Ares, J., D. Ghosal, U. Wienand, P.A. Peterson, and H. Saedler. 1987. The regulatory $C 1$ locus of Zea mays encodes a protein with homology to $M Y B$ proto-oncogene products and with structural similarities to transcriptional activators. EMBO J. 6:3553-3558.

Perrot, G.H. and K.C. Cone. 1989. Nucleotide sequence of the maize $R-S$ gene. Nucleic Acid Res. 17:8003.

Procissi, A., S. Dolfini, A. Ronchi, and C. Tonelli. 1997. Light-dependent spatial and temporal expression of pigment regulatory genes in developing maize seed. Plant Cell 9:1547-1557.

Quattrocchio, F., J.F. Wing, H.T.C. Leppen, J.N.M. Mol, and R.E. Koes. 1993. Regulatory genes controlling anthocyanin pigmentation are functionally conserved among plant species and have distinct sets of target genes. Plant Cell 5:1497-1512.

Radicella, J.P., D. Turks, and V.L. Chandler. 1991. Cloning and nucleotide sequence of a cDNA encoding $B$-Peru, a regulatory protein of the anthocyanin pathway in maize. Plant Mol. Biol. 17:127-130.

Rapisarda, P., S.E. Bellomo, and F. Intrigliolo. 2001. Anthocyanins in blood oranges: Composition and biological activity. Recent Res. Dev. Agr. Food Chem. 5:217-230.

Reforgiato Recupero, G. and G. Puleo. 1994. Classificazione di specie e ibridi di agrumi nella collezione dell'I.S.A. di Acireale. Frutticoltura 11:55-58.

Reforgiato Recupero, G., M.P. Russo, P. Rapisarda, M. La Rosa, M. Guardo, A.R.Lo Piero, and G. Petrone. 2000. Anthocyanin biosynthesis in blood oranges. Proc. Intl. Soc. Citricult. 1:681-682.

Saija, A. 1994. Attività farmacologiche delle antocianine presenti nei succhi pigmentati. Proc. Innovazioni nell'industria dei derivati agrumari. p. 61-66.

Sparvoli, F., C. Martin, A. Scienza, G. Gavazzi, and C. Tonelli. 1994. Cloning and molecular analysis of structural genes involved in flavonoid and stilbene biosynthesis in grape (Vitis vinifera L.). Plant Mol. Biol. 24:743-755.

Tonelli, C., G. Consonni, S. Faccio Dolfini, S.L. Dellaporta, A. Viotti, and G. Gavazzi. 1991. Genetic and molecular analysis of $S n$ a lightinducible, tissue specific regulatory gene in maize. Mol. Gen. Genet. 225:401-410

Torres, A.M., R.K. Soost, and U. Diedenhofen. 1978. Leaf isozymes as genetic markers in citrus. Amer. J. Bot. 65:869-881.

Tsuda, T., M. Yamaguchi, C. Honda, and T. Moriguchi. 2004. Expression of anthocyanin biosynthesis genes in the skin of peach and nectarine fruit. J. Amer. Soc. Hort. Sci. 129:857-862.

Wiering, H. and P. De Vlaming. 1984. Genetics of flower and pollen colours, p. 49-75. In: K.C. Sink (ed.). Petunia. Springer-Verlag, Berlin.

Wrolstad, R.E. 1976. Color and pigment analyses in fruit products. Agr. Expt. Sta. Bul. 624. Oregon State Univ., Corvallis. 